\title{
Effects of surface proteins and lipids on molecular structure, thermal properties, and enzymatic hydrolysis of rice starch
}

\author{
Pan HU ${ }^{1,2}$, Xiaoxu FAN ${ }^{1,2}$, Lingshang LIN $^{1,2}$, Juan WANG ${ }^{1,2}$, Long ZHANG ${ }^{1,2}$, Cunxu WEI ${ }^{1,2 *}$
}

\begin{abstract}
Rice starches with different amylose contents were treated with sodium dodecyl sulfate (SDS) to deplete surface proteins and lipids, and the changes in molecular structure, thermal properties, and enzymatic hydrolysis were evaluated. SDS treatment did not significantly change the molecular weight distribution, crystalline structure, short-range ordered degree, and gelatinization properties of starch, but significantly altered the pasting properties and increased the swelling power of starch. The removal of surface proteins and lipids increased the enzymatic hydrolysis and in vitro digestion of starch. The influences of removing surface proteins and lipids from starch on swelling power, pasting properties, and enzymatic hydrolysis were different among the various starches because of the differences in molecular structures of different starch styles. The aforementioned results indicated that removing the surface proteins and lipids from starch did not change the molecular structure but had significant effects on some functional properties.
\end{abstract}

Keywords: enzymatic hydrolysis; molecular structure; rice starch; surface proteins and lipids; thermal properties.

Practical Application: Surface proteins and lipids of starch and its molecular structure and functional properties.

\section{Introduction}

Starch is synthesized as granules in higher plants and composed of two major components, amylose and amylopectin, and some minor components such as proteins and lipids (Baldwin, 2001; Jaiswal \& Kumar, 2015; Xia et al., 2015). The proteins and lipids within starch granules are normally classified into two types: starch surface and interior proteins and lipids. The starch surface proteins stem from the storage proteins and some matrix proteins that remain absorbed to the surface of starch granules during starch development or after starch extraction, whereas the starch interior proteins stem from the starch biosynthetic or degradative enzymes, which remain following the starch synthesis and are entrapped within starch granules (Baldwin, 2001). The starch surface lipids are loosely attached or absorbed into the surface layers of starch granules in the endosperm, whereas the starch interior lipids are inclined to form a complex with amylose (Morrison, 1995).

The surface proteins and lipids are easily removed from starch using some mild methods not destroying granule structure, while the extraction of interior proteins and lipids of starch needs more disruptive methods (Debet \& Gidley, 2006). The contents of protein and lipid in isolated starch depend on both botanical source and isolation method of starch. In general, grain starch of cereals contains approximately $0.25 \%$ protein and $1.0 \%$ lipid, and root or tuber starches have approximately $0.05 \%$ protein and 0.1\% lipid (Swinkels, 1985; Baldwin, 2001; Wang et al., 2014). Although on a quantitative scale, the proteins and lipids within starch granules are considered negligible, there is increasing awareness that their presence, especially surface proteins and lipids, has significant effects on starch properties and applications.

Numerous studies have shown that the proteins and lipids within starch have significant effects on starch properties but are mainly focused on wheat starch (Debet \& Gidley, 2006; Wang et al., 2014; Blake et al., 2015; Li et al., 2016). It is rarely known about the effects of starch surface proteins and lipids on rice starch properties. In this research, waxy, low- and high-amylose rice starches were treated with sodium dodecyl sulfate (SDS) to deplete granule surface proteins and lipids. The molecular structure, thermal properties, and enzymatic hydrolysis of native and SDS-treated starches were investigated. This study would help to understand the effects of surface proteins and lipids on rice starch properties and provide information for starch applications.

\section{Materials and methods}

\subsection{Plant materials}

An indica rice Te-qing (TQ) and two japonica rice Guang-ling-xiang-nuo (GLXN) and Wu-xing-9915 (WX) were studied in this research. The starches from GLXN, WX, and TQ contain approximately $0.2 \%, 16.8 \%$, and $26.1 \%$ apparent amylose content (AC), respectively (Man et al., 2013) and represent the waxy, low-, and high-amylose rice starches. These rice cultivars were grown in the farm of Yangzhou University in 2015. 


\subsection{Isolation of native starch from brown rice}

The isolation of native starch was described as the method in Wei et al. (2010) with some modifications. Briefly, brown seeds were immersed in deionized water overnight at $4{ }^{\circ} \mathrm{C}$. The softened seeds were extensively ground in a mortar and passed through 100-, 200-, and 400-mesh sieves, successively. After centrifugation, the precipitated starch was washed with water and ethanol, and dried at $40{ }^{\circ} \mathrm{C}$. Finally, the starch was ground through a 100-mesh sieve.

\subsection{Depletion of surface proteins and lipids from starch granules}

The surface proteins and lipids were removed from starch according to a modified method based on that used by Debet and Gidley (2006). The starch slurry $(20 \% \mathrm{w} / \mathrm{v})$ in SDS (2\% w/v) was stirred for $30 \mathrm{~min}$ at $20{ }^{\circ} \mathrm{C}$. Extracted starch was isolated by centrifugation $(5000 \mathrm{~g}, 10 \mathrm{~min}$ ), and repeatedly treated with fresh SDS three times, then washed with water and ethanol. Finally, the sample was freeze-dried with a pressure of $10 \mathrm{~Pa}$ for $24 \mathrm{~h}$ at $-40^{\circ} \mathrm{C}$.

\subsection{Determination of protein content}

The protein content (\%) was calculated from the nitrogen content $(\mathrm{N} \times 6.25)$. The nitrogen content of starch was measured using Elementar Analysensysteme Gmbh Vario EL cube CHN-Nitrogen analyser.

\subsection{Molecular weight distribution analysis of starch}

The starch was debranched with isoamylase and analyzed using Agilent Technologies gel-permeation chromatography (GPC) 220 system according to the method described in Lin et al. (2016).

\subsection{X-ray diffraction (XRD) analysis}

The starch was investigated using Bruker X-ray diffractometer D8 type following the method used by Cai et al. (2015). The sample was exposed to the X-ray beam $(40 \mathrm{kV}, 35 \mathrm{~mA})$ and performed in the diffraction angle $(2 \theta)$ of $3-40^{\circ}$ and a step size of $0.02^{\circ}$.

\subsection{Attenuated total reflectance-Fourier transform infrared (ATR-FTIR) analysis}

The sample was performed using Varian 7000 ATR-FTIR spectroscopy as described in Man et al. (2013). For each measurement, 64 scans with $4 \mathrm{~cm}^{-1}$ resolution were coadded. The spectrum was baseline corrected in the region $1200-800 \mathrm{~cm}^{-1}$ before deconvolution using a $19 \mathrm{~cm}^{-1}$ half-width Lorentzian line and a resolution enhancement factor of 1.9.

\subsection{Swelling power determination of starch}

The swelling power of starch was performed following the method used by Cai et al. (2015). Briefly, the $2 \%$ starch slurry in deionized water was heated for $30 \mathrm{~min}$ at a specific temperature, cooled at room temperature for $10 \mathrm{~min}$, and centrifuged for
$20 \mathrm{~min}$ at $8000 \mathrm{~g}$. The swelling power was the weight ratio of precipitated gel to dry starch.

\subsection{Differential scanning calorimetry (DSC) analysis}

The sample was analyzed using NETZSCH 200-F3 DSC according to the method used by Cai et al. (2015). Briefly, $5 \mathrm{mg}$ starch was weighed and moistened with $15 \mu \mathrm{L}$ of deionized water, then hermetically sealed. After equilibrating for $2 \mathrm{~h}$ at room temperature, the sample was heated to $130^{\circ} \mathrm{C}$ at $10{ }^{\circ} \mathrm{C} / \mathrm{min}$.

\subsection{Rapid visco analyzer (RVA) analysis}

The sample was analyzed using Newport Scientific RVA-3D according to the method used by Fan et al. (2016). Briefly, $8 \%$ starch suspension was equilibrated for $1 \mathrm{~min}$ at $50^{\circ} \mathrm{C}$, heated to $95^{\circ} \mathrm{C}$ at rate of $12{ }^{\circ} \mathrm{C} / \mathrm{min}$, held for $2.5 \mathrm{~min}$ at $95^{\circ} \mathrm{C}$, cooled to $50{ }^{\circ} \mathrm{C}$ at rate of $12{ }^{\circ} \mathrm{C} / \mathrm{min}$, and held for $1.4 \mathrm{~min}$ at $50{ }^{\circ} \mathrm{C}$.

\subsection{Enzymatic hydrolysis determination of starch}

Starch was hydrolyzed by single porcine pancreatic a-amylase (PPA, Sigma A3176) or both PPA and Aspergillus niger amyloglucosidase (AAG, Megazyme E-AMGDF) according to the method used by Lin et al. (2016). Briefly, $10 \mathrm{mg}$ starch was hydrolyzed in $2 \mathrm{~mL}$ of single PPA or both PPA and AAG enzyme solution at $37^{\circ} \mathrm{C}$. Enzymatic hydrolysis was stopped by addition of $2 \mathrm{~mL}$ of $50 \%$ ethanol and $240 \mu \mathrm{L}$ of $0.1 \mathrm{M} \mathrm{HCl}$. After centrifuging (5 min, $14000 \mathrm{~g}$ ), the soluble carbohydrate and glucose content in the supernatant was measured using the anthrone- $\mathrm{H}_{2} \mathrm{SO}_{4}$ method and Megazyme D-Glucose assay kit to quantify the hydrolyzed starch by single PPA and both PPA and AAG, respectively.

\subsection{Hydrolysis kinetics and data fitting}

Starch hydrolysis kinetics was performed using the first-order kinetics following the modified procedures of Zhang et al. (2013) according to the method of Butterworth et al. (2012). The first-order rate equation is $\mathrm{C}=1-\mathrm{e}^{-\mathrm{Kt}}$, where $C$ is the fraction of hydrolyzed starch at hydrolysis time $t$, and $K$ is the hydrolysis rate constant.

\subsection{Statistical analysis}

The data in the tables were the mean and standard deviation of three replicates, and the values with different letters within the same column were significantly different. The significant differences between data were determined by one-way analysis of variance followed by Tukey's test $(p<0.05)$ using SPSS 16.0.

\section{Results and discussion}

\subsection{Effect of SDS extraction on protein content of starch}

Native GLXN, WX and TQ starch had a protein content of $1.41 \%, 1.24 \%$, and $2.49 \%$, which was decreased significantly to $0.07 \%, 0.15 \%$, and $0.61 \%$ by SDS extraction, respectively. The native starch was isolated from brown rice only through water washing and centrifugation, resulting in very high protein content in starch, especially for TQ starch. The low protein content in SDS treated starch agreed with the previous report 
that SDS is the most commonly used reagent to extract proteins and lipids from starch (Debet \& Gidley, 2006). The very low protein content in SDS treated GLXN starch might be related with deficiency of granule-bound starch synthase and existence of micropore in waxy rice starch.

\subsection{Effects of surface proteins and lipids on molecular structure of rice starch}

The molecular weight distribution of starch was assayed using GPC (Figure 1A). In general, the GPC chromatogram of isoamylase-debranched starch exhibits three peaks. Peaks 1 and 2 respectively represent the amylopectin short-branch chains (A and short B chains) and amylopectin long-branch chains (long B chains) branch-chains, and Peak 3 is amylose (Song \& Jane, 2000). GLXN is a waxy rice that does not contain amylose. Therefore, only two peaks were detected in the GPC profile of GLXN starch. Whereas for WX and TQ starches, three peaks were detected in their GPC profiles due to the simultaneous existence of amylose and amylopectin. The percentage of the peak area reflects the molecular weight distribution. In the present research, native GLXN starch consisted of approximately $76.5 \%$ amylopectin short branch-chains and 23.5\% amylopectin long branch-chains; WX and TQ starch had $61.3 \%$ and $54.2 \%$ amylopectin short branch-chains, $19.6 \%$ and $19.7 \%$ amylopectin long branch-chains, and $19.1 \%$ and $26.1 \%$ amylose. SDS treatment did not change the GPC profile and starch component, indicating that surface proteins and lipids had no significant effect on molecular weight distributions of starch (Figure 1A).

Starches are classified into A-, B-, and C-type, and can be detected by their XRD spectra (Man et al., 2013). Native GLXN, WX, and TQ starches all had diffraction peaks of $15^{\circ}$, $17^{\circ}, 18^{\circ}$, and $23^{\circ}$ at $2 \theta$, presenting typical A-type XRD patterns (Figure 1B), but GLXN starch had significantly higher relative crystallinity than WX and TQ starches (Table 1). This result was in accordance with that the relative crystallinity was negatively related to AC (Sevenou et al., 2002). SDS treatment did not influence the crystalline structure and relative crystallinity of rice starch, thereby indicating that surface proteins and lipids had no effect on starch crystallinity.

The short-range ordered degree in starch external region can be detected using ATR-FTIR. The ratio of absorbance $1045 / 1022$ and $1022 / 995 \mathrm{~cm}^{-1}$ reflects the proportion of ordered to amorphous starch and amorphous to ordered carbohydrate structure, respectively (Sevenou et al., 2002). Native GLXN, WX,
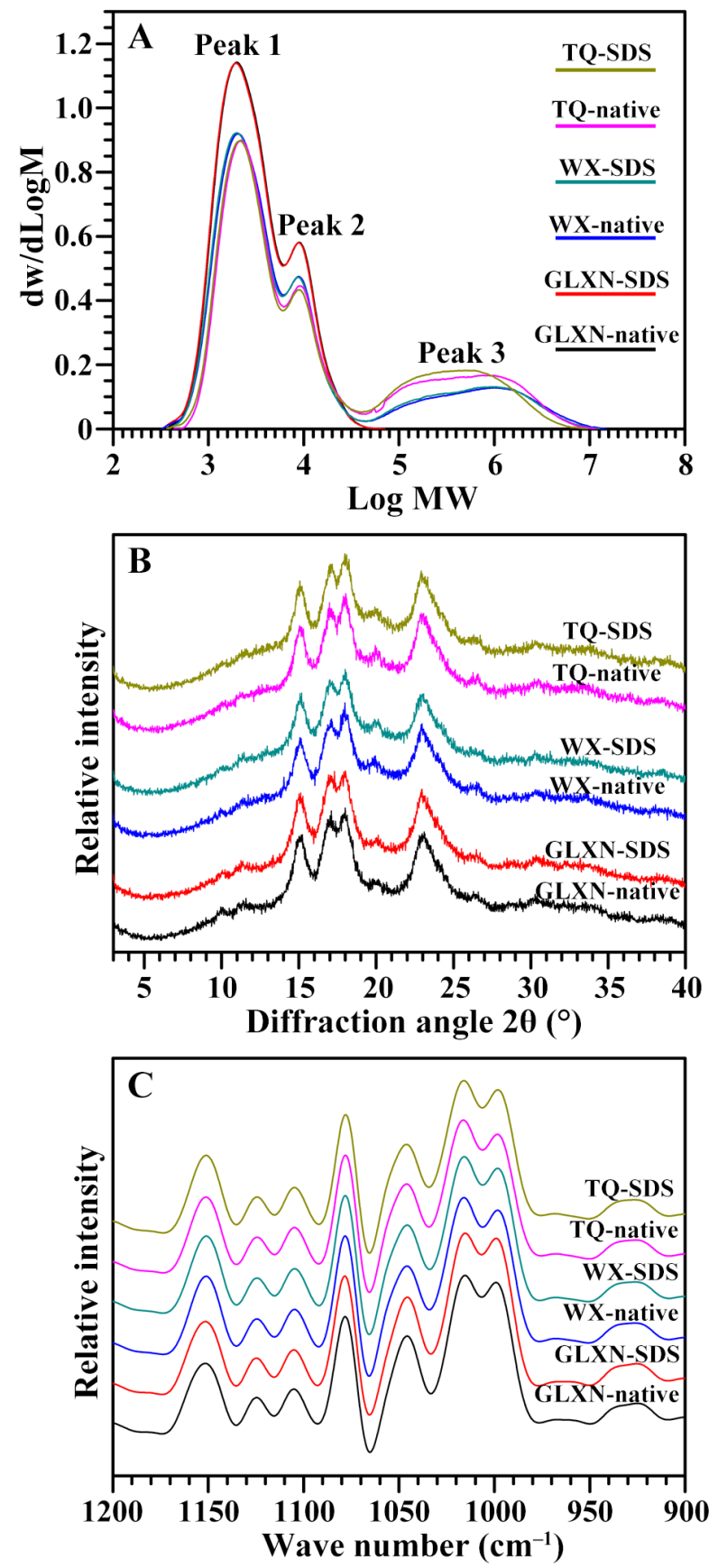

Figure 1. Molecular structure of native and SDS-treated starches. (A) GPC chromatogram of isoamylase-debranched starch; (B) XRD pattern of starch; (C) ATR-FTIR spectrum of starch.

Table 1. Relative crystallinities and IR ratios of native and SDS-treated starches.

\begin{tabular}{cccc}
\hline & Relative crystallinity $(\%)$ & IR ratio \\
\cline { 2 - 4 } & $34.38 \pm 0.14 \mathrm{~b}$ & $0.575 \pm 0.013 \mathrm{~b}$ & $1022 / 995\left(\mathrm{~cm}^{-1}\right)$ \\
\hline GLXN-native & $34.27 \pm 0.53 \mathrm{~b}$ & $0.572 \pm 0.015 \mathrm{~b}$ & $1.052 \pm 0.007 \mathrm{a}$ \\
GLXN-SDS & $28.42 \pm 0.51 \mathrm{a}$ & $0.532 \pm 0.007 \mathrm{a}$ & $1.051 \pm 0.018 \mathrm{a}$ \\
WX-native & $28.09 \pm 0.50 \mathrm{a}$ & $0.530 \pm 0.005 \mathrm{a}$ & $1.107 \pm 0.007 \mathrm{bc}$ \\
WX-SDS & $26.69 \pm 0.71 \mathrm{a}$ & $0.547 \pm 0.003 \mathrm{a}$ & $1.087 \pm 0.002 \mathrm{~b}$ \\
TQ-native & $26.92 \pm 1.50 \mathrm{a}$ & $0.543 \pm 0.003 \mathrm{a}$ & $1.130 \pm 0.025 \mathrm{c}$ \\
TQ-SDS & & $1.086 \pm 0.011 \mathrm{~b}$ \\
\hline
\end{tabular}

Values within a column followed by different letters are significantly different $(\mathrm{p}<0.05)$. 
and TQ starches had similar ATR-FTIR spectra (Figure 1C), but GLXN starch had a significantly higher ratio of absorbance $\left(1045 / 1022 \mathrm{~cm}^{-1}\right)$ and a lower ratio of absorbance $\left(1022 / 995 \mathrm{~cm}^{-1}\right)$ than WX and TQ starches (Table 1). SDS treatment did not significantly change starch FTIR spectra (Figure 1C and Table 1), thereby indicating that the surface proteins and lipids had no effect on the short-range ordered degree in starch external region.

Debet \& Gidley (2006) removed the surface proteins and lipids from starch granules with several solvents including water, $\mathrm{NaCl}$, proteinase $\mathrm{K}$, hexane, water-saturated butanol, 3-[(3-cholamidopropyl) dimethyl-ammonio]-1-propanesulfonate hydrate, and SDS. SDS is the most efficient tested extract that can remove all surface proteins and lipids (Debet \& Gidley, 2006). SDS treatment does not change the morphology and birefringence of granule and the crystalline structure of amylopectin in any starch (Debet \& Gidley, 2006). Therefore, SDS is the most commonly used reagent to extract the surface proteins and lipids from starch (Borén et al., 2008; Zhang et al., 2014). In this study, the depletion of surface proteins and lipids from rice starch with SDS did not change the starch molecular structure including molecular weight distribution, crystalline type and relative crystallinity, and short-range ordered degree (Figure 1, Table 1). These results were paralleled with the conclusion reported by Wang et al. (2014), which $\mathrm{NaOH}$ treatment can extract the surface proteins and lipids from starch but does not influence $\mathrm{AC}$, relative crystallinity, and short-range order of double helice. The above results indicated that surface proteins and lipids had no effect on starch molecular structure.

\subsection{Effects of surface proteins and lipids on thermal properties of rice starch}

The starch swelling power was determined at $5^{\circ} \mathrm{C}$ intervals from 50 to $95{ }^{\circ} \mathrm{C}$ (Figure 2A). For native GLXN starch, the swelling power rapidly increased at 60 and $65^{\circ} \mathrm{C}$, and then stabilized at approximately $37 \mathrm{~g} / \mathrm{g}$ above $70{ }^{\circ} \mathrm{C}$. For native WX starch, the swelling power gradually increased as temperature increased above $60^{\circ} \mathrm{C}$ and reached $19.8 \mathrm{~g} / \mathrm{g}$ at $95^{\circ} \mathrm{C}$. For native TQ starch, the swelling power gradually increased with temperature increase after $70{ }^{\circ} \mathrm{C}$ and reached $16.4 \mathrm{~g} / \mathrm{g}$ at $95^{\circ} \mathrm{C}$. The swelling power reflects the interaction of starch molecules within the amorphous and crystalline regions of granules and depends on the holding water capacity of starch chains through hydrogen bonding. The hydrogen bonds that stabilize the double-helical structure in crystallites are destroyed during heating and are replaced by hydrogen bonds with water (Tester \& Karkalas, 1996). The swelling power is influenced by granule size, AC, amylopectin branch-chains, crystalline structure, and the contents of protein and lipid (Qi et al., 2003; Srichuwong et al., 2005; Debet \& Gidley, 2006; Kaur et al., 2007). The amylopectin content and $\mathrm{AC}$ is positively and negatively correlated with swelling power, respectively (Cai et al., 2015). For GLXN, WX, and TQ starches, the significantly different contents of amylose and amylopectin resulted in their varied swelling powers during heating. SDS treatment significantly increased starch swelling power and agreed with previous reports (Debet \& Gidley, 2006; Wang et al., 2014); thereby indicating that surface proteins and lipids inhibited starch swelling.
The starch gelatinization was measured by DSC, and the thermogram and DSC parameters are presented in Figure 2B and Table 2. For native GLXN, WX, and TQ starches, the different gelatinization properties could arise from their different molecular weight distributions, relative crystallinities, and short-range ordered degree. Removal of surface proteins and lipids had no significant effect on gelatinization properties. The results agreed with a previous study (Debet \& Gidley, 2006), thereby indicating that the removal of surface proteins and lipids had
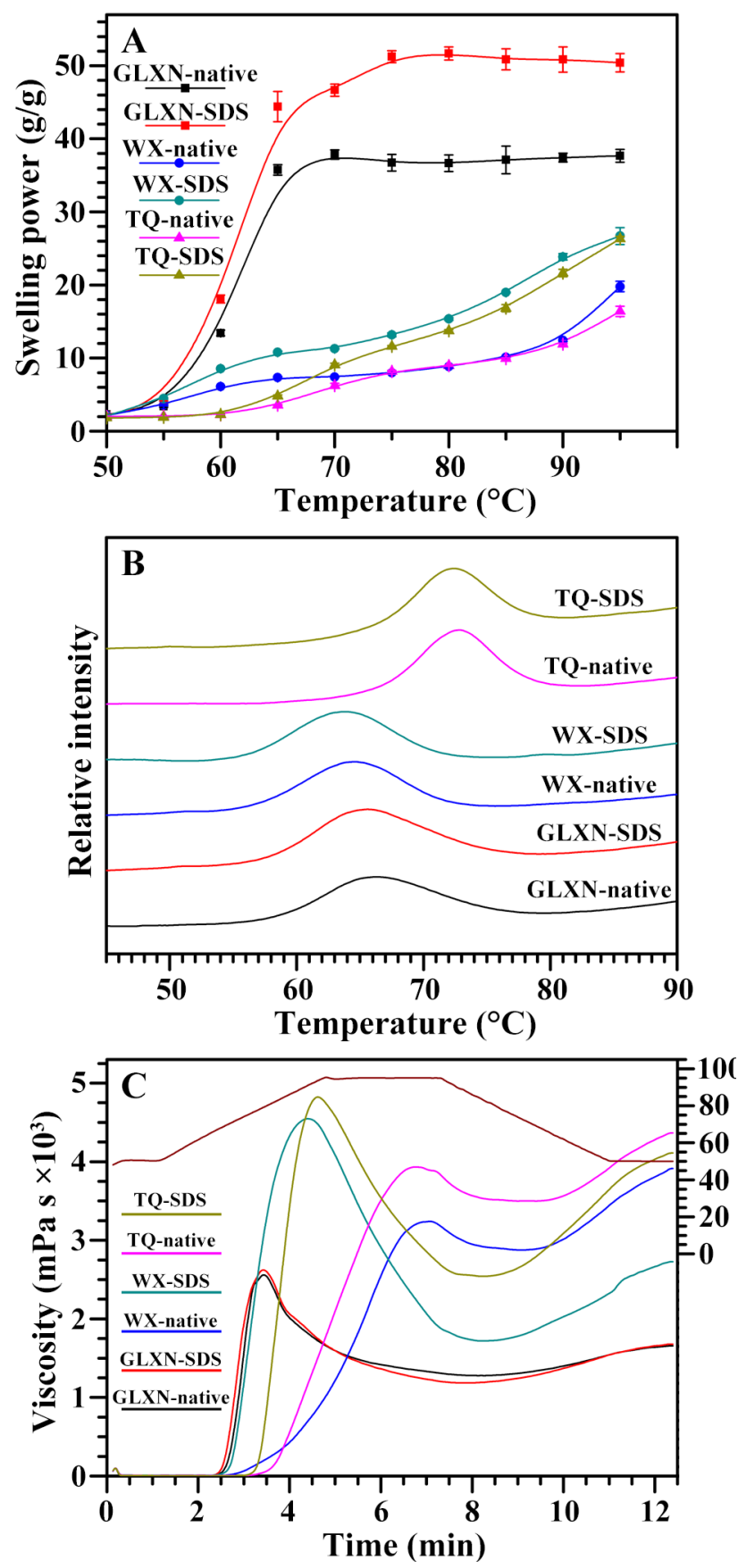

Figure 2. Thermal properties of native and SDS-treated starches. (A) swelling power of starch; (B) DSC thermogram of starch; (C) RVA profile of starch. 
no significant effect on gelatinization properties because the amylopectin crystallite structure was not altered.

The RVA patterns of starches are presented in Figure 2C. For native starch, GLXN, WX, and TQ starch had significantly different pasting properties because of their different molecular structure. GLXN starch had significantly lower pasting viscosity than WX and TQ starch, which was likely a result of increased shear disruption of the high swelling starch granules of GLXN. SDS treatment showed a slight effect on the pasting properties of GLXN starch but a dramatic effect on the pasting properties of WX and TQ starch. The present study agreed with previous reports (Debet \& Gidley, 2006; Wang et al., 2014), thereby showing that surface proteins and lipids had significant influences on the pasting properties of starch.

\subsection{Effect of surface proteins and lipids on enzymatic hydrolysis of rice starch}

In the present study, the starches were enzymatically hydrolyzed by single PPA. The hydrolysis kinetics is shown in Figure 3A. The hydrolysis significantly contained two phases of rapid hydrolysis followed by a slow final phase. The starch hydrolysis data from 0 to $6 \mathrm{~h}$ was fitted according to the first-order rate equation (Zhang et al., 2013), and presented in Figure 3B. The GLXN and TQ starch had the highest and lowest hydrolysis rate coefficient, respectively (Table 3). PPA hydrolyzes starch begins firstly from granule surface, and then it penetrates into granule interior and degrades starch from inside to outside (Li et al., 2004). The starch hydrolysis by PPA is mainly influenced by granule size, porosity, AC, amylopectin fine structure, and crystalline

Table 2. DSC parameters of native and SDS-treated starches.

\begin{tabular}{cccccr}
\hline & $T_{o}\left({ }^{\circ} \mathrm{C}\right)$ & $T_{p}\left({ }^{\circ} \mathrm{C}\right)$ & $T_{c}\left({ }^{\circ} \mathrm{C}\right)$ & $\Delta \mathrm{T}\left({ }^{\circ} \mathrm{C}\right)$ & \multicolumn{1}{c}{$\Delta \mathrm{H}(\mathrm{J} / \mathrm{g})$} \\
\hline GLXN-native & $58.8 \pm 0.1 \mathrm{c}$ & $66.2 \pm 0.2 \mathrm{~d}$ & $76.1 \pm 0.3 \mathrm{~b}$ & $17.3 \pm 0.4 \mathrm{c}$ & $9.72 \pm 0.30 \mathrm{bc}$ \\
GLXN-SDS & $58.1 \pm 0.3 \mathrm{bc}$ & $65.5 \pm 0.1 \mathrm{c}$ & $75.3 \pm 0.6 \mathrm{~b}$ & $17.3 \pm 0.5 \mathrm{c}$ & $10.84 \pm 0.40 \mathrm{~d}$ \\
WX-native & $57.3 \pm 0.5 \mathrm{ab}$ & $64.8 \pm 0.3 \mathrm{~b}$ & $71.1 \pm 0.1 \mathrm{a}$ & $13.8 \pm 0.6 \mathrm{~b}$ & $8.80 \pm 0.05 \mathrm{a}$ \\
WX-SDS & $56.9 \pm 0.7 \mathrm{a}$ & $64.1 \pm 0.3 \mathrm{a}$ & $71.2 \pm 0.2 \mathrm{a}$ & $14.3 \pm 0.5 \mathrm{~b}$ & $9.42 \pm 0.25 \mathrm{~b}$ \\
TQ-native & $67.1 \pm 0.2 \mathrm{~d}$ & $72.6 \pm 0.1 \mathrm{e}$ & $78.0 \pm 0.1 \mathrm{c}$ & $11.0 \pm 0.2 \mathrm{a}$ & $10.06 \pm 0.07 \mathrm{c}$ \\
TQ-SDS & $66.8 \pm 0.3 \mathrm{~d}$ & $72.3 \pm 0.1 \mathrm{e}$ & $78.0 \pm 0.5 \mathrm{c}$ & $11.2 \pm 0.8 \mathrm{a}$ & $10.04 \pm 0.23 \mathrm{c}$ \\
\hline
\end{tabular}

Values within a column followed by different letters are significantly different $(\mathrm{p}<0.05) . T_{o}, T_{p}$ and $T_{c}$ are the gelatinization onset, peak and conclusion temperature, respectively; $\Delta \mathrm{T}$ and $\Delta \mathrm{H}$ are the gelatinization temperature range $\left(T_{c}-T_{o}\right)$ and enthalpy, respectively.
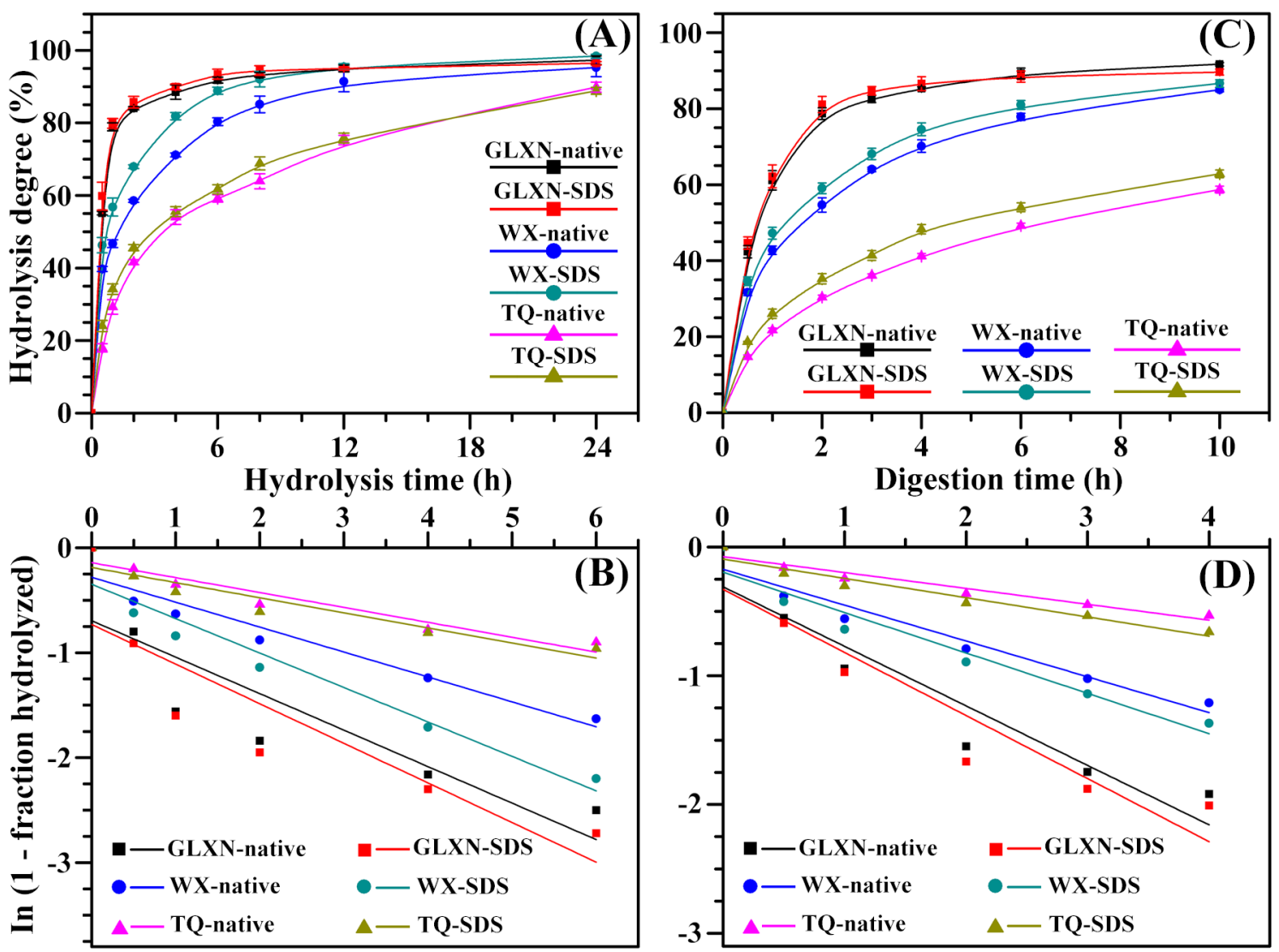

Figure 3. Typical hydrolysis curves (A, C) and first-order kinetics fits (B, D) of native and SDS-treated starches by single PPA (A, B) or both PPA and AAG $(C, D)$. The dots and lines indicate the experimental data of starch hydrolyses and their model-fit or line-fit, respectively. 
Hu et al.

Table 3. Parameters of linear fitting of starch hydrolysis and digestion dynamics.

\begin{tabular}{|c|c|c|c|c|}
\hline & \multicolumn{2}{|c|}{ Hydrolysis by PPA } & \multicolumn{2}{|c|}{ Digestion by both PPA and AAG } \\
\hline & Rate coefficient $\left(\mathrm{h}^{-1}\right)$ & $\mathrm{R}$ value & Rate coefficient $\left(\mathrm{h}^{-1}\right)$ & $\mathrm{R}$ value \\
\hline GLXN-native & $0.349 \pm 0.024 \mathrm{~cd}$ & -0.871 & $0.460 \pm 0.004 \mathrm{e}$ & -0.948 \\
\hline GLXN-SDS & $0.380 \pm 0.025 d$ & -0.884 & $0.488 \pm 0.012 \mathrm{f}$ & -0.945 \\
\hline WX-native & $0.238 \pm 0.008 b$ & -0.961 & $0.278 \pm 0.007 \mathrm{c}$ & -0.971 \\
\hline WX-SDS & $0.328 \pm 0.019 c$ & -0.968 & $0.312 \pm 0.010 \mathrm{~d}$ & -0.971 \\
\hline TQ-native & $0.142 \pm 0.003 a$ & -0.956 & $0.123 \pm 0.001 \mathrm{a}$ & -0.970 \\
\hline TQ-SDS & $0.144 \pm 0.004 \mathrm{a}$ & -0.941 & $0.149 \pm 0.004 b$ & -0.970 \\
\hline
\end{tabular}

Values within a column followed by different letters are significantly different $(\mathrm{p}<0.05)$.

Table 4. The contents of rapidly digestible starch (RDS), slowly digestible starch (SDS), and resistant starch (RS) in native and SDS-treated starches.

\begin{tabular}{cccc}
\hline & RDS (\%) & SDS (\%) & RS (\%) \\
\hline GLXN-native & $32.9 \pm 0.2 \mathrm{e}$ & $46.2 \pm 0.2 \mathrm{e}$ & $20.9 \pm 0.4 \mathrm{~b}$ \\
GLXN-SDS & $34.6 \pm 0.2 \mathrm{f}$ & $46.4 \pm 0.1 \mathrm{e}$ & $19.1 \pm 0.3 \mathrm{a}$ \\
WX-native & $25.4 \pm 0.1 \mathrm{c}$ & $27.8 \pm 0.4 \mathrm{c}$ & $46.9 \pm 0.5 \mathrm{~d}$ \\
WX-SDS & $27.7 \pm 0.3 \mathrm{~d}$ & $30.1 \pm 0.0 \mathrm{~d}$ & $42.2 \pm 0.3 \mathrm{c}$ \\
TQ-native & $13.8 \pm 0.1 \mathrm{a}$ & $16.0 \pm 0.3 \mathrm{a}$ & $70.2 \pm 0.3 \mathrm{f}$ \\
TQ-SDS & $17.2 \pm 0.0 \mathrm{~b}$ & $16.9 \pm 0.5 \mathrm{~b}$ & $65.9 \pm 0.5 \mathrm{e}$ \\
\hline
\end{tabular}

Values within a column followed by different letters are significantly different $(\mathrm{p}<0.05)$.

structure (Blazek \& Gilbert, 2010). The AC is negatively correlated with the starch hydrolysis by amylase, and the pores of waxy starch increased the penetration of amylase, thereby leading to rapid hydrolysis (Li et al., 2004). In the present study, the native starches had significantly different hydrolysis for their different structure, and SDS treatment increased the hydrolysis of starch. When starch is enzymatically hydrolyzed, the surface proteins and lipids of starch can reduce the diffusion of enzymes into granules and block the adsorption site of substrate (Svihus et al., 2005; Wang et al., 2014). Therefore, the depletion of surface proteins and lipids could improve the enzymatic hydrolysis of starch through accelerating the penetration of enzymes into granules and increasing the absorption of enzymes to its substrate.

The in vitro kinetic digestion was investigated by determining the released glucose from starch by both PPA and AAG (Figure 3C). The digestion mechanisms of starches were conspicuously biphasic. The fittings of first-order kinetics to starch digestion processes from 0 to $4 \mathrm{~h}$ are shown in Figure 3D, and the digestion rate and regression coefficients are shown in Table 3. The in vitro digestion was fastest in GLXN starch and slowest in TQ starch. SDS treatment significantly increased the in vitro digestion. Based on the glucose release rate, starch is commonly divided into three fractions: rapidly digestible, slowly digestible, and resistant starch, which is digested within $20 \mathrm{~min}$, digested between 20 and $120 \mathrm{~min}$, and undigested after $120 \mathrm{~min}$, respectively (Englyst et al., 1992). In the present study, the three fractions of native and SDS-treated starches are given in Table 4. SDS treatment significantly increased the content of rapidly digestible starch and decreased the content of resistant starch. The above results were consistent with the report of Wang et al. (2014) that depletion of surface proteins and lipids from starch by $\mathrm{NaOH}$ treatment can increase the in vitro digestion of starch.

\section{Conclusion}

The depletion of surface proteins and lipids from starch did not significantly change the starch molecular weight distribution and crystalline structure. However, the surface proteins and lipids significantly inhibited the swelling power and pasting viscosity of starch and hindered the enzymatic hydrolysis. The influences of removing surface proteins and lipids from starch on the swelling power, pasting properties, and enzymatic hydrolysis were different among the various starches because of the differences in their molecular structure.

\section{Acknowledgements}

This study was financially supported by grants from the National Natural Science Foundation of China (31570324), Natural Science Foundation of Jiangsu Provide (BK20160461), the Qing Lan Project of Jiangsu Province, the Talent Project of Yangzhou University, and the Priority Academic Program Development of Jiangsu Higher Education Institutions.

\section{References}

Baldwin, P. M. (2001). Starch granule-associated proteins and polypeptides: a review. Starch, 53(10), 475-503. http://dx.doi.org/10.1002/1521379X(200110)53:10<475::AID-STAR475>3.0.CO;2-E.

Blake, L. H., Jenner, C. F., Gidley, M. J., \& Cozzolino, D. (2015). Effect of surfactant treatment on swelling behaviour of normal and waxy cereal starches. Carbohydrate Polymers, 125, 265-271. PMid:25857983. http://dx.doi.org/10.1016/j.carbpol.2015.02.049.

Blazek, J., \& Gilbert, E. P. (2010). Effect of enzymatic hydrolysis on native starch granule structure. Biomacromolecules, 11(12), 32753289. PMid:21033657. http://dx.doi.org/10.1021/bm101124t.

Borén, M., Glaring, M. A., Ghebremedhin, H., Olsson, H., Blennow, A., \& Jansson, C. (2008). Molecular and physicochemical characterization of the high-amylose barley mutant Amo1. Journal of Cereal Science, 47(1), 79-89. http://dx.doi.org/10.1016/j.jcs.2007.01.009. 
Butterworth, P. J., Warren, F. J., Grassby, T., Patel, H., \& Ellis, P. R. (2012). Analysis of starch amylolysis using plots for first-order kinetics. Carbohydrate Polymers, 87(3), 2189-2197. http://dx.doi. org/10.1016/j.carbpol.2011.10.048.

Cai, J., Man, J., Huang, J., Liu, Q., Wei, W., \& Wei, C. (2015). Relationship between structure and functional properties of normal rice starches with different amylose contents. Carbohydrate Polymers, 125, 35-44. PMid:25857957. http://dx.doi.org/10.1016/j.carbpol.2015.02.067.

Debet, M. R., \& Gidley, M. J. (2006). Three classes of starch granule swelling: influence of surface proteins and lipids. Carbohydrate Polymers, 64(3), 452-465. http://dx.doi.org/10.1016/j.carbpol.2005.12.011.

Englyst, H. N., Kingman, S. M., \& Cummings, J. H. (1992). Classification and measurement of nutritionally important starch fractions. European Journal of Clinical Nutrition, 46(Suppl 2), S33-S50. PMid:1330528.

Fan, X., Zhang, S., Lin, L., Zhao, L., Liu, A., \& Wei, C. (2016). Properties of new starches from tubers of Arisaema elephas, yunnanense and erubescens. Food Hydrocolloids, 61, 183-190. http://dx.doi. org/10.1016/j.foodhyd.2016.05.015.

Jaiswal, P., \& Kumar, K. J. (2015). Physicochemical properties and release characteristics of starches from seeds of Indian Shahi Litchi. International Journal of Biological Macromolecules, 79, 256-261. PMid:25936503. http://dx.doi.org/10.1016/j.ijbiomac.2015.04.050.

Kaur, L., Singh, J., McCarthy, O. J., \& Singh, H. (2007). Physicochemical, rheological and structural properties of fractionated potato starches. Journal of Food Engineering, 82(3), 383-394. http://dx.doi.org/10.1016/j. jfoodeng.2007.02.059.

Li, J. H., Vasanthan, T., Hoover, R., \& Rossnagel, B. G. (2004). Starch from hull-less barley: V. In-vitro susceptibility of waxy, normal, and high-amylose starches towards hydrolysis by alpha-amylases and amyloglucosidase. Food Chemistry, 84(4), 621-632. http://dx.doi. org/10.1016/S0308-8146(03)00287-5.

Li, W., Gao, J., Wu, G., Zheng, J., Ouyang, S., Luo, Q., \& Zhang, G. (2016). Physicochemical and structural properties of A- and B-starch isolated from normal and waxy wheat: effects of lipids removal. Food Hydrocolloids, 60, 364-373. http://dx.doi.org/10.1016/j. foodhyd.2016.04.011.

Lin, L., Cai, C., Gilbert, R. G., Li, E., Wang, J., \& Wei, C. (2016). Relationships between amylopectin molecular structures and functional properties of different-sized fractions of normal and high-amylose maize starches. Food Hydrocolloids, 52, 359-368. http://dx.doi.org/10.1016/j.foodhyd.2015.07.019.

Man, J., Yang, Y., Huang, J., Zhang, C., Chen, Y., Wang, Y., Gu, M., Liu, Q., \& Wei, C. (2013). Effect of simultaneous inhibition of starch branching enzymes I and IIb on the crystalline structure of rice starches with different amylose content. Journal of Agricultural and Food Chemistry, 61(41), 9930-9937. PMid:24063623. http://dx.doi. org/10.1021/jf4030773.

Morrison, W. R. (1995). Starch lipids and how they relate to starch granule structure and functionality. Cereal Foods World, 40, 437-446.
Qi, X., Tester, R. F., Snape, C. E., \& Ansell, R. (2003). Molecular basis of the gelatinisation and swelling characteristics of waxy rice starches grown in the same location during the same season. Journal of Cereal Science, 37(3), 363-376. http://dx.doi.org/10.1006/jcrs.2002.0508.

Sevenou, O., Hill, S. E., Farhat, I. A., \& Mitchell, J. R. (2002). Organisation of the external region of the starch granule as determined by infrared spectroscopy. International Journal of Biological Macromolecules, 31(1-3), 79-85. PMid:12559430. http://dx.doi.org/10.1016/S01418130(02)00067-3.

Song, Y., \& Jane, J. (2000). Characterization of barley starches of waxy, normal, and high amylose varieties. Carbohydrate Polymers, 41(4), 365-377. http://dx.doi.org/10.1016/S0144-8617(99)00098-3.

Srichuwong, S., Sunarti, T. C., Mishima, T., Isono, N., \& Hisamatsu, M. (2005). Starches from different botanical sources II: contribution of starch structure to swelling and pasting properties. Carbohydrate Polymers, 62(1), 25-34. http://dx.doi.org/10.1016/j.carbpol.2005.07.003.

Svihus, B., Uhlen, A. K., \& Harstad, O. M. (2005). Effect of starch granule structure, associated components and processing on nutritive value of cereal starch: a review. Animal Feed Science and Technology, 122(34), 303-320. http://dx.doi.org/10.1016/j.anifeedsci.2005.02.025.

Swinkels, J. J. M. (1985). Composition and properties of commercial native starches. Starch, 37(1), 1-5. http://dx.doi.org/10.1002/ star.19850370102.

Tester, R. F., \& Karkalas, J. (1996). Swelling and gelatinization of oat starches. Cereal Chemistry, 73, 271-273.

Wang, S., Luo, H., Zhang, J., Zhang, Y., He, Z., \& Wang, S. (2014). Alkaliinduced changes in functional properties and in vitro digestibility of wheat starch: the role of surface proteins and lipids. Journal of Agricultural and Food Chemistry, 62(16), 3636-3643. PMid:24670231. http://dx.doi.org/10.1021/jf500249w.

Wei, C., Qin, F., Zhu, L., Zhou, W., Chen, Y., Wang, Y., Gu, M., \& Liu, Q. (2010). Microstructure and ultrastructure of high-amylose rice resistant starch granules modified by antisense RNA inhibition of starch branching enzyme. Journal of Agricultural and Food Chemistry, 58(2), 1224-1232. PMid:20030326. http://dx.doi.org/10.1021/jf9031316.

Xia, X. J., Li, G. N., Liao, F. R., Zhang, F. S., Zheng, J., \& Kan, J. Q. (2015). Granular structure and physicochemical properties of starches from amaranth grain. International Journal of Food Properties, 18(5), 10291037. http://dx.doi.org/10.1080/10942912.2013.860168.

Zhang, B., Dhital, S., \& Gidley, M. J. (2013). Synergistic and antagonistic effects of a-amylase and amyloglucosidase on starch digestion. Biomacromolecules, 14(6), 1945-1954. PMid:23647443. http://dx.doi. org/10.1021/bm400332a.

Zhang, B., Dhital, S., Flanagan, B. M., \& Gidley, M. J. (2014). Mechanism for starch granule ghost formation deduced from structural and enzyme digestion properties. Journal of Agricultural and Food Chemistry, 62(3), 760-771. PMid:24382148. http://dx.doi.org/10.1021/jf404697v. 